\title{
Konsolide Finansal Tablolar Standardına Göre Edinim Tarihindeki Konsolidasyon Prosedürleri
}

\author{
Aylin POROY ARSOY ${ }^{*}$
}

\section{ÖZET}

TFRS 10 Konsolide Finansal Tablolar'a göre, ana ortaklık bağll ortaklık üzerinde kontrol gücünü elde ettiği tarihte konsolidasyon işlemine başlar ve kontrol gücünü yitirene kadar konsolidasyon işlemine devam eder. TFRS 10, ana ortaklığın bağlı ortaklık üzerindeki kontrol gücünün derecesinin belirlenmesi konusunda bilgiler içerir ve ayrıa edinim tarihinde ve edinim tarihinden sonraki dönemlerde uygulanacak olan konsolidasyon prosedürleri hakkında açıklamalar getirir. TFRS 10, edinim tarihinde şerefiyenin ve kontrol gücü olmayan payların ölçümü konusunda TFRS 3 Işsletme Birleşmeleri'ne atıf yapmaktadır. Bu çalışmanın amacl, muhasebe standartlarl gerekliliklerine göre, edinim tarihinde uygulanacak olan konsolidasyon prosedürlerini incelemek ve edinim tarihinde şerefiyenin ve kontrol gücü olmayan payların değerinin hesaplanmasında kullanılan yöntemleri karşılaştırmaktır.

Anahtar Kelimeler: TFRS 10, TFRS 3, Konsolide Finansal Tablolar, Şerefiye, Kontrol Gücü Olmayan Paylar.

JEL Siniflandirmasi: M40, M41.

\section{Consolidation Procedures at the Date of Acqusition Under Consolidated Financial} Statements Standard

\section{ABSTRACT}

According to TFRS 10 Consolidated Financial Statements, a parent company consolidates a subsidiary from the date on which the parent company first obtains control, and continues consolidating that subsidiary until the date on which control is lost. TFRS 10 includes guidance on how to determine the level of control over the subsidiary, on the other hand also includes consolidation procedures that should be adopted on and after the date of acquisition. TFRS 10 refers to TFRS 3 Business Combinations for measuring goodwill and noncontrolling interests at the date of acquisition. The aim of this study is to examine the consolidation procedures at the date of acquisition and compare the methods that could be applied for calculating goodwill and non controlling interests at the date of acquisition according to accounting standards.

Keywords: TFRS 10, TFRS 3, Consolidated Financial Statements, Goodwill, Noncontrolling Interest.

Jel Classification: M40, M41.

\footnotetext{
* Doç. Dr. Aylin POROY ARSOY, Uludağ Üniversitesi, İktisadi ve İdari Bilimler Fakültesi,
} aporoy@uludag.edu.tr 


\section{GíRiș}

Mayıs 2011'de Uluslararası Muhasebe Standartları Kurulu (IASB) eş zamanlı olarak topluluk muhasebesini konu alan ve beş standarttan oluşan (üç yeni ve iki revize edilmiş) bir standart seti yayınlamıştır. Bu beş standart, konsolidasyon, müşterek anlaşmalar, özsermaye yöntemi ve diğer işletmelerdeki paylara ilişkin açıklamaları tüm yönleri ile kapsamaktadır. Konsolide edilmeyen işletmelerin açıklamaları da ilk defa bu çerçevede ele alınmıştır. Şekil 1'de IASB tarafindan yayınlanan topluluk muhasebesi standartlarının kapsamı izlenebilmektedir.

Şekil 1: Topluluk Muhasebesi Standartları ve Kapsamları

\begin{tabular}{|c|c|c|c|}
\hline & Muhasebe & Dipnotlar & Bireysel finansal tablolar \\
\hline Bağlı ortaklıklar & $\begin{array}{l}\text { UFRS } 10 \text { Konsolide } \\
\text { Finansal Tablolar }\end{array}$ & \multirow{5}{*}{$\begin{array}{c}\text { UFRS } 12 \text { Diğer } \\
\text { İşletmelerdeki Paylara } \\
\text { İlişsin Açıklamalar }\end{array}$} & \multirow{3}{*}{$\begin{array}{l}\text { UMS } 27 \text { Bireysel } \\
\text { Finansal Tablolar }\end{array}$} \\
\hline İştirakler & \multirow{3}{*}{$\begin{array}{l}\begin{array}{l}\text { UMS } 28 \text { İştiraklerdeki } \\
\text { ve İş Ortaklıklarındaki } \\
\text { Yatırımlar }\end{array} \\
\text { UFRS } 11 \text { Müşterek } \\
\text { Anlaşmalar }\end{array}$} & & \\
\hline İş ortaklıkları & & & \\
\hline Müşterek faaliyetler & & & $\begin{array}{l}\text { UFRS } 11 \text { Müşterek } \\
\text { Anlaşmalar }\end{array}$ \\
\hline $\begin{array}{c}\text { Konsolide edilmeyen } \\
\text { yapılandırılmış } \\
\text { işletmeler }\end{array}$ & UFRS 9 / UMS 39 & & $\begin{array}{c}\text { UFRS } 12 \text { Diğer } \\
\text { İşletmelerdeki Paylara } \\
\text { İlişkin Açıklamalar }\end{array}$ \\
\hline
\end{tabular}

Kaynak: KPMG, (2012), Konsolidasyon: Tek Bir Kontrol Modeli, UFRS Bülten Temmuz 2012, Sayı 1, s.6.

Topluluk muhasebesi standartları içinde yer alan IFRS 10 Konsolide Finansal Tablolar'ın geliştirilmesi, eski standart IAS 27'nin Nisan 2002'de IASB'nin gündemine alınması ile başlamıştır. Gündeme alınan projenin amacı, kontrol kavramına dayalı ve tüm işletmeler için geçerli olabilecek tek bir konsolidasyon modeli geliştirmekti. Bu doğrultuda yürütülen proje çalışmaları sürecinde 18 Aralık 2008'de Nihai Taslak (ED 10) Konsolide Finansal Tablolar yayınlandı ve kamuoyunun görüşüne açıldı. Yapılan revizyonlar neticesinde ise, 12 Mayıs 2011'de IFRS 10 Konsolide Finansal Tablolar ve IFRS 12 Diğer İşletmelerdeki Paylara İlişkin Açıklamalar yayınlandı.

IFRS 10 Konsolide Finansal Tablolar, bir işletmenin bir veya birden fazla işletmeyi kontrol ettiğinde düzenlenecek olan konsolide finansal tabloların hazırlanmasına ve sunumuna ilişkin ilkeleri düzenlemektedir. Ayrıca IAS 27 ve SIC 12 Konsolidasyon- Özel Amaçlı İşletmeler'de yer alan kontrol kavramını değiştirerek, kontrolü tanımlayan tek bir model içermektedir. IASB tarafindan IAS 27 ve SIC 12'de yer alan temel konsolidasyon modelinin her zaman ve her ortamda tutarlı olarak uygulanabilir olmadığ IFRS 10, IAS 27 ve SIC 12'deki kavramları kontrol ilkesine dayanan tek bir konsolidasyon 


\section{Muhasebe ve Finansman Dergisi}

modeli çerçevesinde birleştirmektedir. Tüm işletmelerde geçerli olan tek bir konsolidasyon modeli, farklı yapılardaki işletmelerde nasıl bir yol izleneceği konusundaki belirsizliği de ortadan kaldırmaktadır. IFRS 10'da yer alan konsolidasyon modeli, daha önce IAS 27 ve SIC 12 de kısaca ifade edilmiş gereklilikleri açıklığa kavuşturmakta ve ayrıca ek uygulama rehberliği sağlamaktadır (IASB, 2011:5).

Türkiye' de muhasebe standartlarını belirleyici kurum olan Kamu Gözetimi, Muhasebe ve Denetim Standartları Kurulu, IASB'de yaşanan revizyon sürecini takip ederek, "TFRS 10 Konsolide Finansal Tablolar" Standardını 31/12/2012 tarihinden sonra başlayan hesap dönemleri için uygulanmak üzere 28/10/2011 tarih ve 28098 say1lı Resmi Gazetede yayınlanmıştır. Kamu Gözetimi, Muhasebe ve Denetim Standartları Kurulu tarafindan yayınlanan TMS/TFRS' ler IASB tarafından yayınlanan IAS/IFRS setinin tam olarak çevirisi olduğu için, çalışmanın bundan sonraki bölümlerinde sözü geçen standartlar TFRS olarak anılacaktır.

$\mathrm{Bu}$ çalışmanın amacı, TFRS 10 gerekliliklerine göre, edinim tarihinde uygulanacak olan konsolidasyon prosedürlerini incelemek ve edinim tarihinde şerefiyenin ve kontrol gücü olmayan payların değerinin hesaplanmasında kullanılan yöntemleri karşılaştırmaktır. Ülkemizdeki akademik çalışmalarda söz konusu yöntemlerin karşılaştırmalı olarak incelenmemiş olması bu çalışmanın çıkış noktasını oluşturmaktadır.

\section{TFRS 10 KONSOLIDE FINANSAL TABLOLAR VE KONSOLIDASYON PROSEDÜRLERİ}

Ana ortaklık, konsolide finansal tablolarını hazırlarken, benzer koşullardaki benzer işlemler ve olaylar için yeknesak muhasebe politikaları kullanır. Yatırım yapılan işletmenin konsolidasyonu, yatırımcı işletmenin, yatırım yaptığ başlar, kontrolü kaybettiği tarihte de sona erer.(TFRS 10:19-20)

Konsolide finansal tablolar hazırlanırken raporlayan işletme, finansal tablolarda yer alan kalemleri (varlıklar, borçlar, özkaynaklar, gelirler ve giderler ) satır satır birleştirir. Topluluğa ilişkin finansal bilgileri tek bir ekonomik işletme olarak ifade edebilmek için aşağıdaki prosedürler uygulanır: (TFRS 10:B86)

- $\quad$ Ana ortaklığın ve bağlı ortaklıklarının varlık, yükümlülük, özkaynak, gelir, gider ve nakit akışlarına ait benzer kalemleri birleştirilir.

- $\quad$ Ana ortaklığın bağlı ortaklıktaki yatırımının defter değeri ile bağlı ortaklığın özkaynaklarından ana ortaklığın payına isabet eden tutarlar netleştirilir. (elimine edilir)

- Grup işletmeleri arasındaki işlemlerle ilgili grup içi varlık, borç, özkaynak, gelir, gider ve nakit akışlarının tümü elimine edilir.

TFRS 10'da bazı konsolidasyon prosedürlerinde TFRS 3 İşletme Birleşmeleri standardına atıf yapıldığı görülmektedir.

Konsolidasyon sürecinin detayları topluluğun yapısına ve finansal raporlama sistemine bağlı olarak topluluktan topluluğa değişim gösterecektir. Standardın dayandığ1 geleneksel 
yaklaşıma göre, topluluk içinde yer alan işletmeler için her raporlama tarihinde konsolide finansal tablolar hazırlanır. Ancak detaylı iş raporlama sistemleri kullanan büyük topluluklarda bu tür konsolide finansal bilgiler raporlama tarihi itibariyle değil, otomatik olarak ve anlık hazırlanabilmektedir (Grand Thorton, 2011:58).

Konsolidasyon sürecinde yer alan basamaklar ve bu basamaklardaki dikkat edilmesi gereken noktalar Tablo 1'de izlenebilmektedir.

Tablo 1: Konsolidasyon Prosedürleri

\begin{tabular}{|c|c|}
\hline$B A S A M A K L A R$ & ÖNEMLI KONULAR \\
\hline $\begin{array}{l}\text { BASAMAK } 1 \text { - toplulukta yer alan tüm işletmelerin } \\
\text { finansal tablolarının birleştirilmesi }\end{array}$ & $\begin{array}{ll}\text { - } & \text { Benzer muhasebe politikaları } \\
\text { - } & \text { Aynı olmayan raporlama tarihleri } \\
\text { - } & \text { Yabancı ülkelerdeki bağlı ortaklıklar } \\
\text { - } & \text { Önemsiz bağlı ortaklıklar (kontrol gücü } \\
\text { olmayan) } \\
\text { - } \quad \text { Topluluk yapısındaki değişiklikler }\end{array}$ \\
\hline $\begin{array}{l}\text { BASAMAK 2- topluluk içi işlemlerin ve bakiyelerin } \\
\text { eliminasyonu }\end{array}$ & $\begin{array}{ll}\text { - } & \text { Topluluk içi zararlar ve kazançlar } \\
\text { - } & \text { Vergi etkileri } \\
\text { - } & \text { Sinıflandırmayı etkileyen topluluk } \\
& \text { anlaşmalar }\end{array}$ \\
\hline $\begin{array}{l}\text { BASAMAK } 3 \text { - her bir bağlı ortaklıktaki ana ortaklık } \\
\text { yatırımının eliminasyonu ve şerefiyenin ve diğer } \\
\text { düzeltmelerin kayıtlanması }\end{array}$ & $\begin{array}{l}\text { - } \quad \text { Düzeltme kayıtlarının yapılması } \\
\text { - } \quad \text { Şerefiyenin itfası }\end{array}$ \\
\hline $\begin{array}{l}\text { BASAMAK 4- kapsamlı karın ve özsermayenin } \\
\text { kontrol gücü olmayan paylara dağıtımı }\end{array}$ & 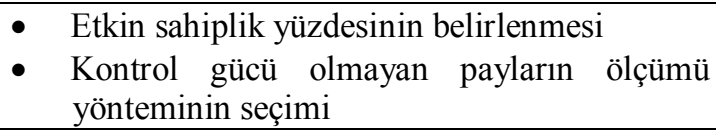 \\
\hline
\end{tabular}

Kaynak: Grand Thornton.2011.Under Control: A practical Guide to Applying IFRS 10 Consolidated Financial Statements, s.52.

\section{EDINIM TARIHINDE ŞEREFIYENIN VE KONTROL GÜCÜ OLMAYAN PAYLARIN BELIRLENMESI}

Edinim tarihinde, henüz topluluğa dahil şirketler arasında eliminasyon gerektirecek işlemler ortaya çıkmadan önce yapılan hem şerefiyenin hem de kontrol gücü olmayan payların hesaplanması işlemi, konsolidasyon sürecinin başlangıcını oluşturmaktadır. TFRS 10 edinim tarihindeki bu işlemler için TFRS 3 İşletme Birleşmeleri'ne atıf yapmaktadır.

TFRS 3'de kontrol gücü olmayan paylar "doğrudan veya dolaylı olarak ana şirkete atfedilemeyen, bir bağlı ortaklıktaki özkaynak" olarak tanımlanmaktadır. Benzer bir tanım TFRS 10 'da da bulunmaktadır.

Ana ortaklığın, bağlı ortaklığın \%100'ünden daha az bir paya sahip olması durumunda, konsolide finansal tabloların düzenlenmesinde ayrı bir prosedür ortaya çıkmaktadır. Bu durumda kontrol gücü olmayan payların belirlenmesi ve konsolide finansal tablolarda sunulması gerekmektedir. Kontrol gücü olmayan paylar, konsolide finansal durum tablosunda özkaynaklarda ayrı bir kalem olarak yer alır. Kontrol gücü olmayan payların belirlenmesinde iki farklı yöntem bulunmaktadır: (TFRS 3: 19)

a) Kontrol gücü olmayan payların gerçeğe uygun değer ile ölçümü ile veya; 


\section{Muhasebe ve Finansman Dergisi}

b) Kontrol gücü olmayan payların bağlı ortaklığın net varlıklarının orantılı payı üzerinden ölçümü.

İki yöntemde kontrol gücü olmayan paylar farklı şekillerde hesaplanacağı için şerefiye tutarı da farklılaşacaktır.

İki yöntemin uygulanmasında üç tür farklılık ortaya çıkmaktadır: (Ernst \& Young, 2013:638-639)

- Kontrol gücü olmayan payların bağlı ortaklığın net varlıklarının orantılı payı üzerinden ölçümü yöntemi uygulandığında; kontrol gücü olmayan paylar ve şerefiye tutarları; kontrol gücü olmayan payların gerçeğe uygun değer ile ölçümü yöntemine göre daha düşük hesaplanacaktır.

- $\quad$ Eğer şerefiyenin dağıtıldığı nakit yaratan birim sonraki dönemlerde değer düşüklüğüne uğrarsa, kar veya zarara aktarılan şerefiyenin itfasına ilişkin tutarlar, kontrol gücü olmayan payların gerçeğe uygun değer ile ölçümü yönteminde daha düşük hesaplanacaktır.

Üçüncü fark, ana ortaklığın daha sonraki dönemlerde bağlı ortaklığın daha fazla hissesini edinimi ile ortaya çıkacaktır. Edinim tarihinde kontrol gücü olmayan payların net varlıklarının orantılı payı üzerinden ölçümü yöntemi benimsenmişse, gerçeğe uygun değer üzerinden yapılan yeni bir hisse alımı için kontrol gücü olmayan paylardaki azalış tutarı daha yüksek olacaktır.

\subsection{Kontrol Gücü Olmayan Payların Gerçeğe Uygun Değer İle Ölçümü}

Kontrol gücü olmayan payların gerçeğe uygun değer ile ölçümünde, bağlı ortaklığın tüm varlık ve kaynak kalemlerinin gerçeğe uygun değeri ile konsolide finansal tablolara alınması amaçlanmaktadır. Bağlı ortaklığın tüm varlık ve kaynak kalemleri, aynı zamanda özkaynaklarında ortaya çıkan değer artışı; edinim tarihinde gerçeğe uygun değerleri ile kayda alınacaktır. Ayrıca, ana ortaklığın kontrol ettiği paylara düşen kısmı ile kontrol gücü olmayan paylara düşen kısmını gösterecek şekilde şerefiyenin de hesaplanması gerekmektedir.

Örneğin ${ }^{1}$, 1 Ocak 2015'de A şirketi, B şirketinin \%80 oranındaki sermaye payına tekabül eden toplam 6.000 adet hisse senedine 150.000 TL ödeyerek sahip olmuştur. A şirketi kontrol gücü olmayan payların gerçeğe uygun değer ile ölçümüne karar vermiştir.

$150.000 \mathrm{TL}, \mathrm{B}$ şirketinin \%80 oranındaki hisselerinin gerçeğe uygun değeri olduğuna göre; \%20 oranındaki kontrol gücü olmayan payların gerçeğe uygun değeri;

$(150.000 / 0,80) \times \% 20=37.500$ TL olarak hesaplanır.

\footnotetext{
${ }^{1}$ Konuya ilişkin örnek "Mackenzie Bruce, Coetsee Danie, Njikizana Tapiwa, Chamboko Raymond, Colyvas Blaise, Hanekom Brandon. 2013. Interpretation and Application of International Financial Reporting Standards, Wiley, USA s.266-270'de verilen yaklaşım doğrultusunda hazırlanmıştır.
} 
The Journal of Accounting and Finance

January/2016 A VE B ŞİKETI 1 OCAK 2015 TARIHLI FINANSAL DURUM TABLOLARI (KONSOLIDASYON ÖNCESI)

\begin{tabular}{|l|r|r|}
\hline & \multicolumn{1}{|c|}{ A ŞiRKETí } & \multicolumn{1}{|c|}{ B ŞíRKETí } \\
\hline VARLIKLAR & & 56.100 \\
\hline Kasa & 196.350 & 13.650 \\
\hline Alıcılar & 51.300 & 24.150 \\
\hline Stoklar & 34.350 & 75.000 \\
\hline Tesis, makine ve cihazlar & 150.000 & -15.000 \\
\hline Birikmiş amortismanlar (-) & -31.500 & 15.000 \\
\hline Haklar & 0 & 168.900 \\
\hline TOPLAM VARLIKLAR & 400.500 & 9.900 \\
\hline & & 0 \\
\hline KAYNAKLAR & 6.000 & 97.500 \\
\hline Satıclar & 150.000 & 61.500 \\
\hline Borç senetleri & 172.500 & 168.900 \\
\hline Sermaye & 72.000 & 0 \\
\hline Geçmiş yıl karları & 400.500 & \\
\hline TOPLAM KAYNAKLAR & & \\
\hline
\end{tabular}

B şirketinin net varlıkları, varlıklar toplamından borçların düşülmesi suretiyle bulunur: $168.900-9.900=159.000 \mathrm{TL}$

Edinim tarihinde B şirketinin varlık ve borçlarının gerçeğe uygun değerleri şu şekilde tespit edilmiştir:

\begin{tabular}{|c|c|c|c|}
\hline & Defter değeri & $\begin{array}{c}\text { Gerçeğe uygun } \\
\text { dĕger }\end{array}$ & Fark \\
\hline Kasa & 56.100 & 56.100 & 0 \\
\hline Alıcilar & 13.650 & 13.650 & 0 \\
\hline Stoklar & 24.150 & 25.650 & 1.500 \\
\hline Tesis, makine ve cihazlar (net) & 60.000 & 72.000 & 12.000 \\
\hline Haklar & 15.000 & 19.500 & 4.500 \\
\hline Satıcilar & -9.900 & -9.900 & 0 \\
\hline TOPLAM & 159.000 & 177.000 & 18.000 \\
\hline
\end{tabular}

Tesis, makine ve cihazların net defter değeri 60.000 TL dir. (75000 eksi \%20 amortisman). Tesis makine ve cihazların yenileme maliyeti brüt 90.000 TL olarak belirlenmiş; \%20 amortisman payı (18.000) düşüldükten sonra net gerçeğe uygun değeri 72.000 TL olarak bulunmuştur. Yapılan bu gerçeğe uygun değer ölçümünde hesaplanan toplam 18.000 TL lık gerçeğe uygun değer ölçüm farkının 14.400 TL lık kısmı (18.000 


\section{Muhasebe ve Finansman Dergisi}

$\mathrm{x} \% 80) \mathrm{A}$ ana ortaklığın payına düşen kısım; 3.600 TL lık kısmı ise (18.000 x\%20) B bağlı ortaklığın payına düşen kısımdır.

Kontrol gücü olmayan payların ve şerefiyenin hesaplanması aşağıdaki gibi yapılır:

\begin{tabular}{|l|l|}
\hline Edinim maliyetinin gerçeğe uygun değeri & 150.000 \\
\hline$(+)$ Kontrol gücü olmayan payların gerçeğe uygun değeri & 37.500 \\
\hline (-) B şirketinin net varlıklarının gerçeğe uygun değeri & $(177.000)$ \\
\hline ŞEREFiYE & $\mathbf{1 0 . 5 0 0}$ \\
\hline Şerefiyenin ana ortaklığın payına düşen kısmı: 10.500 x \%80 = 8.400 TL \\
\hline Şerefiyenin kontrol gücü olmayan paylara düşen kısmı: 10.500 x \%20=2.100 TL \\
\hline
\end{tabular}

A ana ortaklık ve B bağlı ortaklığın eliminasyon kayıtlarının ilki; A ana ortaklığın "Bağlı Ortaklıklar Hesabı" ile B bağlı ortaklığın özkaynak hesapları arasında gerçekleştirilir. Bu kayıtla ayrıca, kontrol gücü olmayan payların \%20 lik bölümünün de ayrıca konsolide finansal durum tablosunda gösterilmesi sağlanır. Zira konsolidasyon işleminde, kontrol gücü olmayan payların bulunması durumunda, özkaynak eliminasyon kaydı, ana ortaklığın bağ 1 ortaklığa olan yatırımının yüzde oranı dahilinde yapılır.

Öncelikle, B bağlı ortaklığın özkaynağı ile A ana ortaklığın yatırımının eliminasyonu yapılır. B şirketinin 97.500 TL lik sermaye tutarının \%80'1 olan 78.000 TL ve 61.500 TL lık geçmiş yıl karlarının \%80’1 olan 49.200 TL eliminasyon kaydında yer alır. Ayrıca B bağlı ortaklığının varlık ve kaynaklarının gerçeğe uygun değer ile ölçümünden kaynaklanan farkların "Gerçeğe Uygun Değer Ölçüm Farkı Hesabı"na alınması kaydı gerçekleştirilir. Gerçeğe Uygun Değer Ölçüm Farkı Hs., kontrol gücü olmayan payların gerçeğe uygun değer ile ölçümü yöntemi kullanıldığında, bağlı ortaklığın varlık ve kaynaklarının defter değerleri ve gerçeğe uygun değerleri arasındaki farkların izlendiği hesaptır.

Sermaye Hs.(B Şti.) 78.000

Geçmiş Yıl Karları Hs.(B Şti.) 49.200

Gerçeğe Uygun Değer Ölçüm Farkı Hs. 18.000

Şerefiye Hs. 10.500

Bağlı Ortaklıklar (A Şti)

150.000

Kontrol gücü olmayan payların yeniden değerleme payı

3.600

Kontrol gücü olmayan payların şerefiye payı

2.100

Daha sonra, "Gerçeğe Uygun Değer Ölçüm Farkı Hesabı"nda bulunan 18.000 TL 1ık tutarın B bağlı ortaklığının ilgili kalemlerine dağıtımı yapılır. Bu kayıt sayesinde konsolide finansal durum tablosunda, B bağlı ortaklığın varlık ve kaynak kalemlerinin gerçeğe uygun değerleri ile gösterilmesi sağlanmış olur. Bu iki kayıt, "Gerçeğe Uygun Değer Ölçüm Farkı Hs." kullanılmadan tek kayıt ile de gerçekleştirilebilir. 
Stoklar Hs. $\quad 1.500$

Tesis, Makine ve Cihazlar Hs. $\quad 15.000$

Haklar Hs. $\quad 4.500$

Birikmiş Amortismanlar Hs. $\quad 3.000$

Gerçeğe Uygun Değer Ölçüm Farkı Hs. $\quad 18.000$

Konsolide çalışma kağıdından da izlenebileceği gibi konsolide finansal durum tablosunun pasifinde yer alacak olan kontrol gücü olmayan paylar 37.500 TL lik tutarının dağılımı şu şekildedir:
B bağlı ortaklığının sermayesinin \%20’u
19.500
B bağlı ortaklığının geçmiş yıl karlarının \%20’u
12.300
Kontrol gücü olmayan payların yeniden değerleme payı
3.600
Kontrol gücü olmayan payların şerefiye payı
$\underline{2.100}$

\subsection{TL}

Edinim tarihinde A ana ortaklık ve B bağlı ortaklığın konsolide çalışma kağıtları şu şekilde düzenlenir: 
Muhasebe ve Finansman Dergisi

\section{Ocak / 2016}

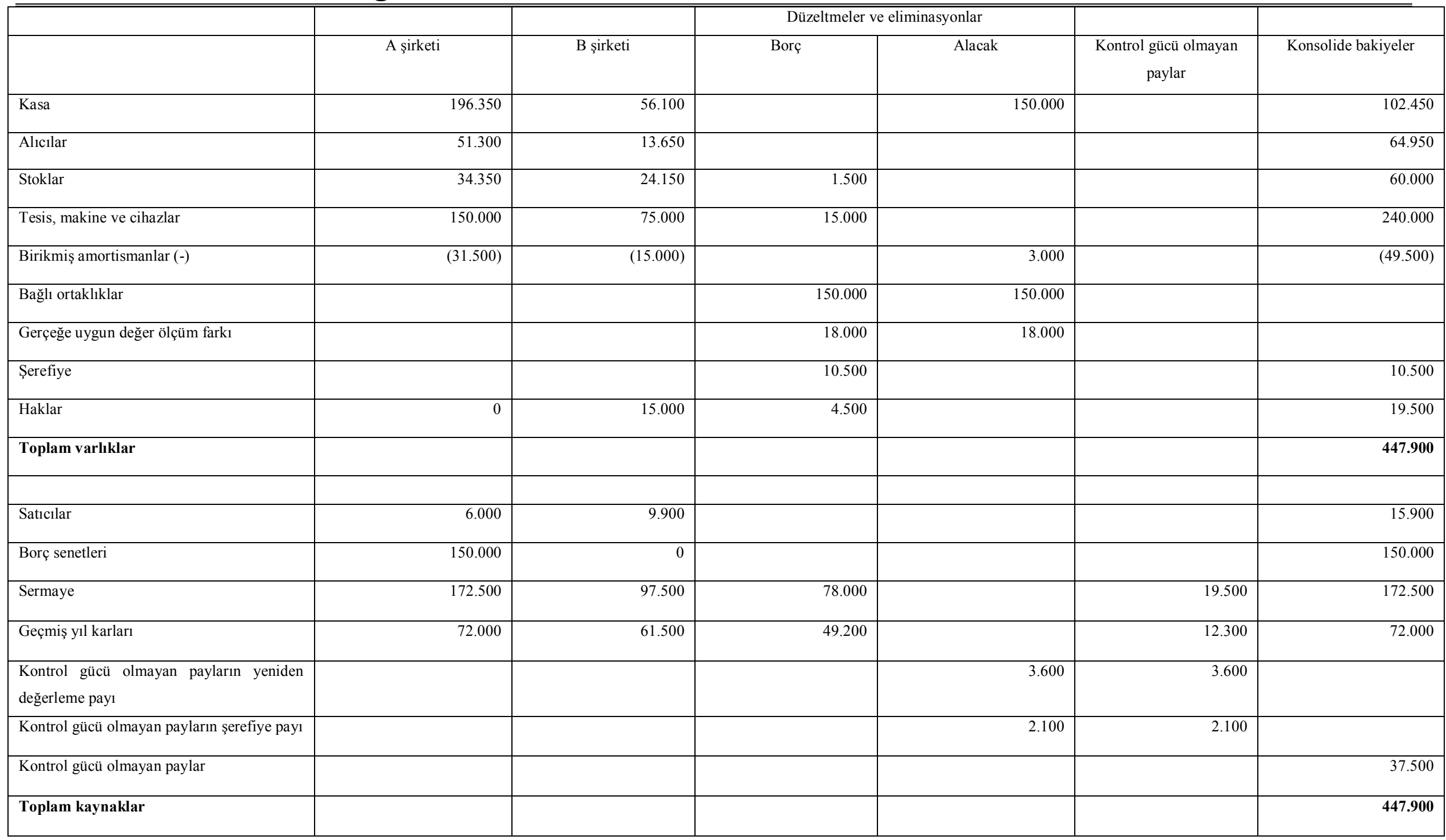


$\mathrm{Bu}$ verilere göre $\mathrm{A}$ ana ortaklığının konsolide finansal durum tablosu şu şekilde düzenlenir:

\begin{tabular}{|l|r|}
\hline \multicolumn{2}{|c|}{ A ANA ORTAKLIK 1 Ocak 2015 TARIHLI } \\
KONSOLIDE FINANSAL DURUM TABLOSU \\
\hline VARLIKLAR & $\underline{\mathbf{4 4 7 . 9 0 0}}$ \\
\hline Kasa & 102.450 \\
\hline Alıcılar & 64.950 \\
\hline Stoklar & 60.000 \\
\hline Tesis, makine ve cihazlar & 240.000 \\
\hline Birikmiş amortismanlar (-) & $(49.500)$ \\
\hline Şerefiye & 10.500 \\
\hline Haklar & 19.500 \\
\hline AKTİF TOPLAMI & $\mathbf{4 4 7 . 9 0 0}$ \\
\hline BORCLAR & $\underline{\mathbf{1 6 5 . 9 0 0}}$ \\
\hline Satıcılar & 15.900 \\
\hline Borç senetleri & 150.000 \\
\hline ÖZKAYNAKLAR & $\underline{\mathbf{2 8 2 . 0 0 0}}$ \\
\hline Sermaye & 172.500 \\
\hline Geçmiş yll karları & 72.000 \\
\hline Kontrol gücü olmayan paylar & 37.500 \\
\hline PASiF TOPLAMI & $\mathbf{4 4 7 . 9 0 0}$ \\
\hline
\end{tabular}

Eliminasyon kayıtlarında A ana ortaklığının "Bağlı Ortaklıklar Hesabı”ndaki yatırımı ile B bağlı ortaklığının özsermayesi elimine edildiği için, konsolide finansal durum tablosunda, B bağlı ortaklığının özermayesi yer almaz. Yalnızca kontrol gücü olmayan payların (\%20) özkaynak payı pasifte gösterilir.

\subsection{Kontrol Gücü Olmayan Payların Bağlı Ortaklığın Net Varlıklarının Orantılı Payı Üzerinden Ölçümü}

Kontrol gücü olmayan payların bağlı ortaklığın net varlıklarının orantılı pay1 üzerinden ölçümü yönteminde, edinim tarihinde bağlı ortaklığın tüm varlık ve kaynaklarının ve aynı zamanda kontrol gücü olmayan payların yatırım değerinin gerçeğe uygun değerleri ile konsolide finansal tablolara alınması sağlanır. Bu yöntemin kontrol gücü olmayan gerçeğe uygun değer ile ölçümü yönteminden fark1, şerefiyenin sadece ana ortaklığa ait olmasıdır. Bağlı ortaklığa herhangi bir şerefiye tutarı atfedilmeyecektir. 


\section{Muhasebe ve Finansman Dergisi}

Örneğin2, yukarıda verilmiş olan A ana ortaklık ve B bağlı ortaklık örneğini, kontrol gücü olmayan payların hesaplanmasında kullanılan ikinci yöntem olan "kontrol gücü olmayan payların bağlı ortaklığın net varlıklarının orantılı payı üzerinden ölçümü” yöntemi ile şu şekilde çözebiliriz.

\begin{tabular}{|l|r|}
\hline Edinim maliyetinin gerçeğe uygun değeri & 150.000 \\
\hline$(+)$ Kontrol gücü olmayan payların gerçeğe uygun değeri & 37.500 \\
\hline (-) B şirketinin net varlıklarının gerçeğe uygun değeri & $(177.000)$ \\
\hline ŞEREFiYE & $\mathbf{1 0 . 5 0 0}$ \\
\hline Şerefiyenin ana ortaklığın payına düşen kısmı: 10.500 x \%80 $=8.400 \mathrm{TL}$ \\
\hline
\end{tabular}

Eliminasyon kayıtlarının ilki, A ana ortaklığın bağlı ortaklıklar hesabı ile B bağlı ortaklığın özkaynak hesapları arasında yapılır. B şirketinin 97.500 TL lık sermaye tutarının \%80'1 olan 78.000 TL ve 61.500 TL lık geçmiş yıl karlarının \%80’1 olan 49.200 TL eliminasyon kaydında yer alır. Şerefiye sadece A ana ortaklığın payına düşen kısmı ifade etmektedir.

\begin{tabular}{lr}
\hline Sermaye Hs.(B Şti.) & 78.000 \\
Geçmiş Yı1 Karları Hs.(B Şti.) & 49.200 \\
Gerçeğe Uygun Değer Ölçüm Farkı Hs. & 18.000 \\
Şerefiye Hs. & 8.400
\end{tabular}

Bağlı Ortaklıklar (A Şti)

150.000

Kontrol gücü olmayan payların yeniden değerleme payı $\quad 3.600$

Daha sonra, “ Gerçeğe Uygun Değer Ölçüm Farkı Hesabı”nda bulunan 18.000 TL lık tutarın B bağlı ortaklığının ilgili kalemlerine dağıtımı yapılır. Bu kayıt sayesinde konsolide finansal durum tablosunda, B bağlı ortaklığın varlık ve kaynak kalemlerinin gerçeğe uygun değerleri ile gösterilmesi sağlanmış olur. 
$\begin{array}{ll}\text { Stoklar Hs. } & 1.500\end{array}$

Tesis, Makine ve Cihazlar Hs. $\quad 15.000$

Haklar Hs. $\quad 4.500$

Birikmiş Amortismanlar Hs. $\quad 3.000$

Gerçeğe Uygun Değer Ölçüm Farkı Hs. 18.000

Konsolide çalışma kağıdından da izlenebileceği gibi konsolide finansal durum tablosunun pasifinde yer alacak olan kontrol gücü olmayan paylar 35.400 TL lik tutarının dağılımı şu şekildedir:

$\begin{array}{lr}\text { B bağlı ortaklığının sermayesinin \%20’u } & 19.500 \\ \text { B bağlı ortaklığının geçmiş yıl karlarının \%20’u } & 12.300 \\ \text { Kontrol gücü olmayan payların yeniden değerleme payı } & \underline{3.600}\end{array}$

35.400 TL

Edinim tarihinde A ana ortaklık ve B bağlı ortaklığın konsolide çalışma kağıtları şu şekilde düzenlenir: 
Muhasebe ve Finansman Dergisi

Ocak /2016

\begin{tabular}{|c|c|c|c|c|c|c|}
\hline & & & $\overline{\text { Düzeltmeler v }}$ & asyonlar & & \\
\hline & A şirketi & B şirketi & Borç & Alacak & $\begin{array}{l}\text { Kontrol gücü } \\
\text { olmayan paylar }\end{array}$ & Konsolide bakiyeler \\
\hline Kasa & 196.350 & 56.100 & & 150.000 & & 102.450 \\
\hline Alıcilar & 51.300 & 13.650 & & & & 64.950 \\
\hline Stoklar & 34.350 & 24.150 & 1.500 & & & 60.000 \\
\hline Tesis, makine ve cihazlar & 150.000 & 75.000 & 15.000 & & & 240.000 \\
\hline Birikmiş amortismanlar (-) & $(31.500)$ & $(15.000)$ & & 3.000 & & $(49.500)$ \\
\hline Bağlı ortaklıklar & & & 150.000 & 150.000 & & \\
\hline Gerçeğe uygun değer ölçüm fark1 & & & 18.000 & 18.000 & & \\
\hline Şerefiye & & & 8.400 & & & 8.400 \\
\hline Haklar & 0 & 15.000 & 4.500 & & & 19.500 \\
\hline Toplam varlıklar & & & & & & 445.800 \\
\hline Satıcilar & 6.000 & 9.900 & & & & 15.900 \\
\hline Borç senetleri & 150.000 & 0 & & & & 150.000 \\
\hline Sermaye & 172.500 & 97.500 & 78.000 & & 19.500 & 172.500 \\
\hline Geçmiş yıl karları & 72.000 & 61.500 & 49.200 & & 12.300 & 72.000 \\
\hline $\begin{array}{l}\text { Kontrol gücü olmayan payların } \\
\text { yeniden değerleme payı }\end{array}$ & & & & 3.600 & 3.600 & \\
\hline Kontrol gücü olmayan paylar & & & & & & 35.400 \\
\hline Toplam kaynaklar & & & & & & 445.800 \\
\hline
\end{tabular}


$\mathrm{Bu}$ verilere göre $\mathrm{A}$ ana ortaklığının konsolide finansal durum tablosu şu şekilde düzenlenir:

\begin{tabular}{|c|c|}
\hline \multicolumn{2}{|c|}{$\begin{array}{l}\text { A ANA ORTAKLIK } 1 \text { Ocak } 2015 \text { TARİHLI } \\
\text { KONSOLİDE FİNANSAL DURUM TABLOSU }\end{array}$} \\
\hline VARLIKLAR & $\underline{445.800}$ \\
\hline Kasa & 102.450 \\
\hline Alıcilar & 64.950 \\
\hline Stoklar & 60.000 \\
\hline Tesis, makine ve cihazlar & 240.000 \\
\hline Birikmiş amortismanlar (-) & $(49.500)$ \\
\hline Şerefiye & 8.400 \\
\hline Haklar & 19.500 \\
\hline AKTIFF TOPLAMI & 445.800 \\
\hline$\underline{B O R C L A R}$ & $\underline{165.900}$ \\
\hline Satıcilar & 15.900 \\
\hline Borç senetleri & 150.000 \\
\hline$\underline{O ̈ Z K A Y N A K L A R}$ & $\underline{279.900}$ \\
\hline Sermaye & 172.500 \\
\hline Geçmiş yıl karları & 72.000 \\
\hline Kontrol gücü olmayan paylar & 35.400 \\
\hline PASİF TOPLAMI & 445.800 \\
\hline
\end{tabular}

Eliminasyon kayıtlarında A ana ortaklığının “Bağlı ortaklıklar Hesabı”ndaki yatırımı ile B bağlı ortaklığının özsermayesi elimine edildiği için, konsolide finansal durum tablosunda, B bağlı ortaklığının özermayesi yer almaz. Yalnızca kontrol gücü olmayan payların (\%20) özkaynak payı pasifte gösterilir. $\mathrm{Bu}$ yöntemde şerefiye sadece $\mathrm{A}$ ana ortaklığın payını gösterecek şekilde finansal tablolara alındığı için; 8.400 TL olarak raporlanır.

\section{SONUÇ}

Konsolide finansal tablolar bir ekonomik topluluk içinde yer alan birden fazla işletmenin finansal durumunu gösteren muhasebe raporları olarak ifade edilmektedir. Konsolide finansal tablolar tek bir şirket için düzenlenen tablolar olmayıp, şirketler topluluğu için düzenlenen tablolardır. Konsolide bilgiler olmadan, topluluğun finansal durumu hakkında 


\section{Muhasebe ve Finansman Dergisi}

bilgi sahibi olmak mümkün değildir. Konsolide bilgiler sayesinde topluluğun gerçek finansal durumu, finansal performansı ve nakit akışı hakkında güvenilir sonuçlar elde edilir.

Bireysel işletmelerde yöneticiler, ileriye dönük kararlar alırken veya işletmenin mevcut finansal durumunu görmek isterken işletmenin mali tablo verilerine ihtiyaç duyar. İçlerinde birden fazla işletmeyi barındıran ekonomik topluluklarda yöneticilerin alacakları kararların önemi daha da artmaktadır. Çünkü bu gibi ekonomik topluluklarda alınacak olan yanlış bir karar veya topluluğun mevcut mali durumu hakkında yapılacak olan yanlış bir tespit, tek bir işletmeyi değil, zincirleme olarak tüm ekonomik topluluğun geleceğini etkileyecektir. Bu açıdan, ekonomik topluluğun tümünü ilgilendiren bir karar alırken veya ekonomik topluluğun mevcut performansını değerlendirirken, sadece ana şirketin veya bağlı ortaklıklardan birinin finansal tablo verilerine dayanarak sonuca varması, yöneticiyi yanlış kararlara sürükleyecektir. Topluluklara dair kararlar alınırken yöneticiler konsolide finansal tabloların sunduğu bilgilere ihtiyaç duyarlar.

IASB'nin Mayıs 2011'de topluluk muhasebesi için yayınladığ 1 beş standart ile topluluğa dahil işletmelerin finansal raporlarını hazırlama ve sunma ilkelerini açıklığa kavuşturmuştur. $\mathrm{Bu}$ standartlar içerisinde yer alan IFRS 10, ana ortaklık- bağlı ortaklık ilişkisini sahiplik yüzdesi yerine kontrol gücü kavramına dayandırmakta ve konsolidasyon prosedürlerini içermektedir.

Topluluk işletmelerinin IASB'nin yayınladığ uygulamaları hem konsolide finansal tablolarının doğru, güvenilir ve gerçeğe uygun sunumunu sağlayacak, hem de bağlı ortaklıkların, iştiraklerin ve iş ortaklıklarının yatırımcı işletmenin finansal tabloların güncel bir şekilde izlenmesine olanak tanıyacaktır.

Türkiye'de konsolide finansal tablo hazırlama yükümlülüğü bulunan topluluk işletmeleri açısından Türk Ticaret Kanunu'nda 2011 yılında yapılan revizyon ile yeni bir dönem açılmıştır. Daha önce yasal mevzuatımızda ayrıntılı yer bulamayan işletme birleşmeleri ve topluluk muhasebesi gibi konular TTK'da artık ele alınmaktadır. Diğer yandan TTK, Kamu Gözetimi, Muhasebe ve Denetim Standartları Kurulu'nun uluslararası muhasebe ve finansal raporlama standartlarını Türkçe'ye çevirmek suretiyle yayınladı̆̆ı TMS/TFRS 'leri referans olarak göstermektedir. $\mathrm{Bu}$ gelişmeler ülkemizde faaliyet gösteren topluluk işletmelerinin doğru, güvenilir ve gerçeğe uygun finansal raporlama yapmaları açısından atılmış önemli adımlardır. 


\section{KAYNAKLAR}

IASB (2011), Effect Analysis, IFRS 10 Consolidated Financial statements and IFRS 12 Disclosure of Interests in Other Entities.

KPMG (2012), Konsolidasyon: Tek Bir Kontrol Modeli, UFRS Bülten Temmuz 2012, Sayı 1.

Mackenzie Bruce, Coetsee Danie, Njikizana Tapiwa, Chamboko Raymond, Colyvas Blaise, Hanekom Brandon (2013), Interpretation and Application of International Financial Reporting Standards, Wiley, USA.

TFRS 10 Konsolide Finansal Tablolar, 28/10/2011 tarih ve 28098 say1lı Resmi Gazete

TFRS 3 İşletme Birleşmeleri, 31/03/2006 tarih ve 26125 sayılı Resmi Gazete

Grand Thornton (2011), Under Control: A practical Guide to Applying IFRS 10 Consolidated Financial Statements.

The International Financial Reporting Group of Ernst\&Young (2013), International GAAP 2013 Volume 1, Ernst\&Young and Wiley, USA. 